\title{
Post COVID-19 Symptoms: A Neglected Domain
}

\section{Chhaya Mittal $^{1}$, Abhishek Mishra², Seema Jain ${ }^{3}$, Neelam S Gautam ${ }^{4}$}

${ }^{1}$ Associate Professor, Department of Community Medicine, Lala Lajpat Rai Memorial Medical College, Meerut; ${ }^{2}$ junior resident, Department of Community Medicine, Lala Lajpat Rai Memorial Medical College, Meerut; ${ }^{3}$ Professor Department of Community Medicine, Lala Lajpat Rai Memorial Medical College, Meerut; ${ }^{4}$ Assistant Professor Department of Community Medicine, Lala Lajpat Rai Memorial Medical College, Meerut

\begin{tabular}{|c|c|c|c|c|c|c|c|}
\hline Abstract & Introduction & Methodology & $\underline{\text { Results }}$ & Conclusion & References & Citation & Tables / Figures \\
\hline \multicolumn{8}{|c|}{ Corresponding Author } \\
\hline \multicolumn{7}{|c|}{$\begin{array}{l}\text { Dr Chhaya Mittal, R11, Lala Lajpat Rai Memorial Medical College, Meerut, Uttar Pradesh } \\
\text { E Mail ID: } \underline{\mathrm{dr} \text { chhaya04@yahoo.co.in }}\end{array}$} & 回部回 \\
\hline
\end{tabular}

\section{Citation}

Mittal C, Mishra A, Jain S, Gautam NS. Post COVID-19 Symptoms: A Neglected Domain. Indian J Comm Health. 2021;33(2):325-328. https://doi.org/10.47203/IJCH.2021.v33i02.018

Source of Funding: Nil Conflict of Interest: None declared

\section{Article Cycle}

Received: 27/03/2021; Revision: 05/05/2021; Accepted: 30/05/2021; Published: 30/06/2021

This work is licensed under a Creative Commons Attribution 4.0 International License.

\section{Abstract}

Background: COVID -19 is the most important public health problem of recent time. Most people who have COVID-19 recovers completely within a few weeks but some people continue to have symptoms after initial recovery. Objective: To assess the prevalence of Post COVID symptoms, to assess requirement of treatment and to make recommendation for Post COVID care. Methods: Present cross sectional study was done among patients who recovered from COVID-19 in Meerut district. Mobile numbers of COVID patients were obtained from records, Total 100 randomly selected patients were contacted using google form and information regarding post covid symptoms in between 6 weeks to 12 weeks after recovery from COVID was obtained. Result: $87 \%$ patients developed one or more post covid symptoms. Weakness was reported to be most common problem (55\%), followed by body ache (26\%) and neuropsychiatric symptoms such as difficulty in concentration and insomnia (22\%). Every fifth patient reported that symptoms persisted for more than 1 month. Though most of the respondents classified their symptoms as mild and moderate (52.5\% and $37.9 \%$ respectively), $47 \%$ of the symptomatic patients have to take some treatment for these symptoms. Conclusion: Post COVID symptoms are common but usually less severe. Some form of treatment was required to deal with problem. Almost one in five patients reported that symptoms persisted for more than one month. The results highlight the need for post Covid care for COVID recovered patients.

\section{Keywords}

\section{COVID-19; Post COVID Symptoms; Cross Sectional Study; Post COVID Treatment.}

\section{Introduction}

COVID-19 is the most import public health problem of recent time. It is the disease caused by a new corona virus called SARS-CoV-2. Corona viruses are a large family of viruses which may cause illness in animals or humans. In humans, several corona viruses are known to cause respiratory infections ranging from the common cold to more severe diseases such as Middle East Respiratory Syndrome (MERS) and Severe Acute Respiratory Syndrome (SARS). The most recently discovered corona virus causes corona virus disease COVID-19(1).

WHO first learned of this new virus on 31 December 2019, following a report of a cluster of cases of 'viral pneumonia' in Wuhan, People's Republic of China, Since then it has spread all over the world.(2)

Most people who have coronavirus disease 2019 (COVID19) recover completely within a few weeks. But some people even those who had mild versions of the disease continue to experience symptoms even after their initial recovery. These people sometimes describe themselves as "long haulers" and the condition has been called postCOVID-19 syndrome or "long COVID-19."(3)

Older people and people with many serious medical conditions are the most likely to experience lingering COVID-19 symptoms, but even young, otherwise healthy people can feel unwell for weeks to months after infection. The most common signs and symptoms that linger over time include: -Fatigue, Shortness of breath, 
Cough, Joint pain, Chest pain, Other long-term signs and symptoms may include: - Muscle pain or headache, Fast or pounding

heartbeat, Loss of smell or taste, Memory, concentration or sleep problems, rash and hair loss(3). The latest study by the Journal of American Medical Association (JAMA) shows that a rare multisystem inflammatory illness could be developed in some of the Covid-19 survivors. This could turn into a major challenge for public health across the world.(4)An overwhelming majority (94.9\%) experienced at least one post-COVID-19 symptom, with fatigue (82.9\%) being the most prevalent post-discharge manifestation.(5) Over past one year we have progressed in many aspects of COVID prevention and treatment. India has developed and maintained a large infrastructure for successful treatment of patients suffering from COVID 19, we have also progressed in field of vaccination, but post COVID care is still lacking at many places. To provide care for post COVID symptoms it is very important to understand actual magnitude and severity of problem.

As presently not much work has been done to understand post COVID problems, this study has been planned and conducted to decide actual need of post COVID care.

\section{Aims \& Objectives}

1. To assess the prevalence and severity of Post COVID19 Symptoms.

2. To assess the treatment required.

3. To make recommendation for Post COVID-19 care.

\section{Material \& Methods}

Present cross-sectional study was conducted at LLRM medical college, Meerut. Data was obtained from L.L.R.M. Medical College. Sample size was calculated assuming prevalence of post COVID symptoms as 50\%, $10 \%$ allowable error and 95\% confidence interval using the formulae $N=(1.96) 2 \mathrm{PQ} / \mathrm{D} 2$. Sample size thus calculated came out to be 96 . However, this is rounded about to 100 . The list of patients with their mobile number was developed and 100 patients were selected by using simple random sampling.

All positive patients (RT-PCR, TRUNAT Positive and Rapid Antigen positive patients) were included. Both hospital admitted and home isolation patients were taken. Information was collected from those patients who recovered from COVID. Criteria for recovery was taken as either RTPCR negative or completed 14 days isolation and no symptoms. Post covid symptoms are considered as those symptoms which develop after recovery from COVID.

Google form regarding variable parameters patient experienced during course of illness and after recovery was developed in Hindi. All the selected candidates were contacted telephonically and explained in detail about study and information regarding filling and submitting Google form was given. Thereafter Google form sent on their registered mobile number. Information regarding various aspects of COVID and post-COVID problems, treatment behaviour and illness behaviour was collected.

\section{Results}

In present study total 100 patients were interviewed. Out of these $60 \%$ were males and $40 \%$ were females. Among various age group $57 \%$ patient belong to $20-40$ age group,35\% belong to $40-60$ age group while only $8 \%$ were 60 years and above. No respondent was below 20 years of age.

When patients were asked about their most probable source of infection $75 \%$ think that they contacted infection from their place of work, another $9 \%$ received infection from home, $8 \%$ got infection while travelling or shopping and another $6 \%$ from neighborhood and friends. $2 \%$ were not able to comment regarding their probable source of infection.(Table 1)

All the patients were interviewed whether they suffered any health issue after being declared as recovered from COVID 19 illness. Out of total $87 \%$ of study subjects developed post COVID symptoms. Generalized weakness following COVID was found to be most common symptom and was observed in $55 \%$ of respondents. another common symptom being body-ache including muscle and joint pain (26\%) followed by neuropsychiatric symptoms such as Insomnia, Loss of concentration (22\%). 19\% patients were having restlessness and giddiness, while $17 \%$ patients observed respiratory symptoms such as running nose, sore throat, chest tightness and breathlessness etc. Headache and palpitation were another common symptom ( $15 \%$ and $14 \%$ respectively).

Some patients also reported loss of taste and smell (9\% and $7 \%$ respectively). Fever chest pain and rise in Blood pressure and rise in blood sugar were reported only in $1 \%$ of respondents. $13 \%$ of the respondents did not develop any symptom at all.

Out of these 87 patients, 36 patients (41\%) were having only one symptom and most common being weakness and body ache. $21(24 \%)$ patients reported to have $1-3$ symptoms, $18(21 \%)$ were having 3-5 symptoms while 12 patient $(14 \%) s$ had more than 5 health problems as a sequelae to COVID. (Table 2)

Participants who reported post COVID symptoms were asked about their perception regarding severity of symptoms. $52.9 \%$ classified these symptoms as mild symptom, $37.9 \%$ perceived their problems as of moderate severity, while only $8.1 \%$ perceived their symptoms as severe while only $1 \%$ perceived it as very severe.(Figure 1) When inquired regarding duration of symptoms among those who had symptoms in post COVID recovery phase $37(42.5 \%)$ had symptoms for less than 15 days, $32(36.8 \%)$ had for $15-30$ days while $18(20.7 \%)$ experienced symptoms persist for more than one month.(Figure 2) Respondents who developed some symptoms in post COVID recovery phase when enquired regarding need of treatment, 53\% reported that they have not taken any 
treatment at all and their symptoms improved on their own without any treatment, while $47 \%$ of them had taken treatment.

Out of those who took any type of treatment it was observed that people preferred multiple treatment options simultaneously. Allopathic medicines were preferred $(47.4 \%)$, while home remedies being second choice, taken by $32.9 \%$. Another $13.2 \%$ took ayurvedic medicine while $2.6 \%$ had also taken homeopathic medicine.

\section{Discussion}

Out of total study participants $60 \%$ were males and $40 \%$ were females. While in a study done by Helpin SJ et al males were $54 \%$ and females were $46 \%$. (6) Huang $C$ et al also observed that male were $52 \%$.(7)

Among various age group $57 \%$ patient belong to $20-40$ age group,35\% belong to $40-60$ age group. When it was compared with corona virus cases in India as of July 9, 2020 , it was observed that maximum patients belonged to $60-74$ years age group and $45-59$ years age group $(40.2 \%$ and $35.1 \%$ respectively).(8) Median age was found to be 57 years by Huang $C$ et al.(7)

Workplace was found to be most probable place of infection as 3/4th of total patients acquired infection from their workplace highlighting the need of workplace etiquettes for preventing spread of COVID and also other respiratory illnesses as workplace are usually close and overcrowded places. Also strictly following social distancing and use of mask is need of the hour as market and neighborhood are also a common place where peoples usually got infection.

In present study $87 \%$ of study subjects developed post COVID symptoms. More than half of recovered patients developed generalized weakness following COVID, another common symptom being body-ache including muscle and joint pain (26\%) This is in accordance with study done by Helpin SJ et al in UK where they reported fatigue, breathlessness, and psychological distress at 7 weeks after discharge from hospital with a clinically significant drop in the quality of life of many individuals. Fatigue as a symptom was observed in $60 \%$ ward admitted and $72 \%$ in ICU admitted patients. They also recommended rehabilitation care for COVID-19 survivors (6). In another study from Oslo Norway by Knut Stavem, Waleed Ghanima in 2020 has shown that persistent fatigue (46\%) is common from 1.5-6 months after COVID19 in a non-hospitalized population (9).

In present study neuropsychiatric symptoms such as Insomnia, Loss of concentration was observed in $22 \%$, almost similar findings were observed by Huang $C$ et al. they observed sleep difficulty in $26 \%$ while anxiety and depression were observed in $22 \%$. (7)

$17 \%$ patients observed respiratory problems in present study while Helpin SJ observed 50\% patients developed breathlessness. (6)
$15 \%$ of the respondents also reported to have headache in post COVID recovery phase. There are isolated studies reporting persistence of headache as a symptom in recovery phase by Pedro et al at USA (10).

palpitation was found to be another common problem of patients in post covid recovery phase. Palpitation in form of tachycardia was also reported by Suet-Ting Lau et al in Hong Kong. (11)

Corona virus is supposed to have effect on nervous system also. Which is reflected commonly among patients as loss of taste and smell. But these symptoms were also reported to persist 6weeks to 12 weeks after recovery in present study. $7 \%$ patient have loss of smell while $9 \%$ have loss of taste even after recovery from COVID. Similar findings were observed by Vaira LA et al in a study in Italy in 2020, they recorded that at the end of the observation period (observation time 6, 60 days after symptom onset), 5.8 per cent patients had moderate to severe olfactory dysfunction while 4.3 percent patients had a significant taste disorder (12).

Another problem reported was hair fall (16\%). Hair loss is very common after any acute illness, probable cause may be compromised nutrition of patients and decreased immunity.

As almost $80 \%$ patients considered their post covid symptoms as mild to moderate, so there is very less need of hospitalization for post covid care, but appropriate medication is required for improving quality of life in these patients.

Even $20 \%$ patients feel some problems more than one month after recovery, further highlighting need of appropriate treatment.

Respondents who developed some symptoms in post COVID recovery phase when enquired regarding need of treatment, 53\% reported that they have not taken any treatment at all and their symptoms improved on their own without any treatment, while $47 \%$ of them had taken treatment. Though allopathic medicine was preferred by patients, there is need for appropriate treatment guidelines.

\section{Conclusion}

Most of patients suffered one or another problem even after recovery from COVID. Involvement of CNS, respiratory system and CVS was also observed along with generalized weakness and joint pains. Though usually they are mild to moderate and 4 in 5 patients recovered by the end of a months after recovery from COVID, but $20 \%$ patients are having health issues even long time after recovery from acute illness.

\section{Recommendation}

It was observed that almost $87 \%$ patient developed post covid symptoms, it is recommended to study further these issues on a large sample and for a longer duration to understand them better. There should be follow up of patients at monthly interval for 6 months. Role of diet and 
INDIAN JOURNAL OF COMMUNITY HEALTH / VOL 33 / ISSUE NO 02 / APR- JUN 2021 exercise also seems to be important and need to be studied. There is need to develop dedicated post COVID care clinics for better recovery of patients. It is need of hour to develop some guidelines for patients regarding when they should seek medical care.

\section{Relevance of the study}

There is need of care even after recovery from COVID, as individual suffering is high even during recovery period.

\section{Authors Contribution}

All authors have contributed equally.

\section{References}

1. Information Regarding COVID-19 Vaccine. (2021). Retrieved 9 June 2021, from https://www.mohfw.gov.in/covid vaccination/ vaccination/index.html

2. Retrieved 9 June 2021, from https://www.who.int/docs/defaultsource/coronaviruse/situation-reports/20200121-sitrep-1-2019ncov.pdf

3. COVID-19 (coronavirus): Long-term effects. (2021). Retrieved 9 June 2021, from https://www.mayoclinic.org/diseasesconditions/coronavirus/in-depth/coronavirus-long-termeffects/art-20490351

4. Available on: Why post-recovery symptoms could prove dangerous for Covid-19 survivors - DIU News (indiatoday.in)

5. Iqbal A, Iqbal K, Arshad Ali S, Azim D, Farid E, Baig MD et al. The COVID-19 sequelae: a cross-sectional evaluation of post-recovery

\section{Tables}

\section{TABLE 1 PREVALENCE OF POST COVID SYMPTOMS}

\begin{tabular}{|l|l|}
\hline Type of symptom & No. and \% $(\mathrm{n}=100)$ \\
\hline Weakness & 26 \\
\hline Body ache & 22 \\
\hline Neuro-psychiatric symptoms & 19 \\
\hline restlessness and Giddiness & 17 \\
\hline Respiratory symptoms & 16 \\
\hline Hair fall & 15 \\
\hline Headache & 14 \\
\hline Palpitation & 09 \\
\hline Loss of taste sensation & 07 \\
\hline Loss of smell sensation & 1 \\
\hline Chest pain \& High B.P. & 1 \\
\hline Blood sugar raised & 13 \\
\hline No symptoms & \\
\hline
\end{tabular}

\section{Figures}

FIGURE 1 POST COVID-19 SYMPTOMS

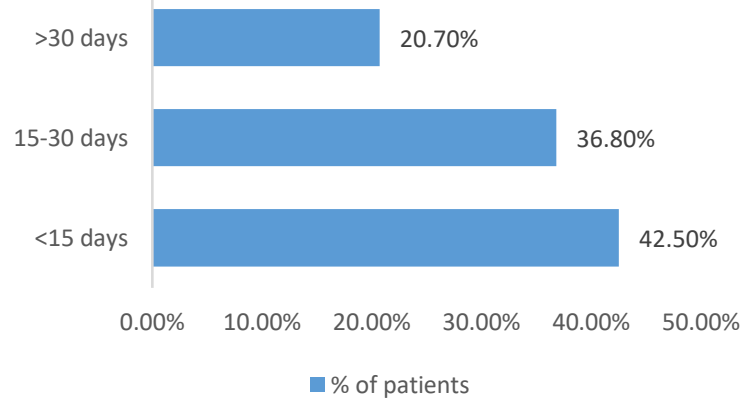

[Post COVID-19 Symptoms...] | Mittal C et al symptoms and the need for rehabilitation of COVID-19 survivors. Cureus. (2021) 13:e13080. 10.7759/cureus.13080 - DOI - PMC PubMed

6. Halpin SJ, Mclvor C, Whyatt G, Adams A, Harvey O, McLean L et al. Post discharge symptoms and rehabilitation needs in survivors of COVID-19 infection: A cross-sectional evaluation. J MedVirol.2021;93(2):1013-1022.

7. Huang C, Huang L, Wang Y, Li X, Ren L, Gu X et al. 6-month consequences of COVID-19 in patients discharged from hospital: a cohort study. Lancet 2021; 397: 220-32

8. India - COVID-19 cases by age group 2020 | Statista. (2021). Retrieved 9 June 2021, from https://www.statista.com/statistics/1110522/india-number-ofcoronavirus-cases-by-age-group/

9. Stavem K, Ghanima W, Olsen MK, Gilboe HM, Einvik Prevalence and Determinants of Fatigue after COVID-19 in Non-Hospitalized Subjects: A Population-Based Study. Int. J. Environ. Res Public Health. 2021 Feb 19; 18(4):2030.

10. Rocha-Filho PAS, Voss L. Persistent Headache and Persistent Anosmia Associated with COVID-19. Headache 2020;60:17971799.

11. Lau ST, Yu WC, Mok NS, Tsui PT, Tong WL, Cheng SW. Tachycardia amongst subjects recovering from severe acute respiratory syndrome (SARS). Int J Cardiol. 2005 Apr 8;100(1):167-9.

12. Vaira LA, Hopkins C, Petrocelli M, ,Lechien JR, Chiesa Estomba CM, Salzano $\mathrm{G}$ et al. Smell and taste recovery in coronavirus disease 2019 patients: a 60-day objective and prospective study. J Laryngol \& Otol. 2020;134(8):703-9.

TABLE 2 PERCEPTION OF PATIENTS REGARDING SEVERITY OF POST COVID 19 SYMPTOMS

\begin{tabular}{|ll|}
\hline Severity of post COVID symptom & No (\%) \\
\hline Mild & $46(52.9)$ \\
\hline Moderate & $33(37.9)$ \\
\hline Severe & $7(8.1)$ \\
\hline Very severe & $1(1.1)$ \\
\hline Total & $87(100)$ \\
\hline
\end{tabular}

FIGURE 2 PREFERENCE OF TREATMENT AMONG PATIENTS WHO DEVELOPED POST COVID 19 SYMPTOMS (MULTIPLE RESPONSE)

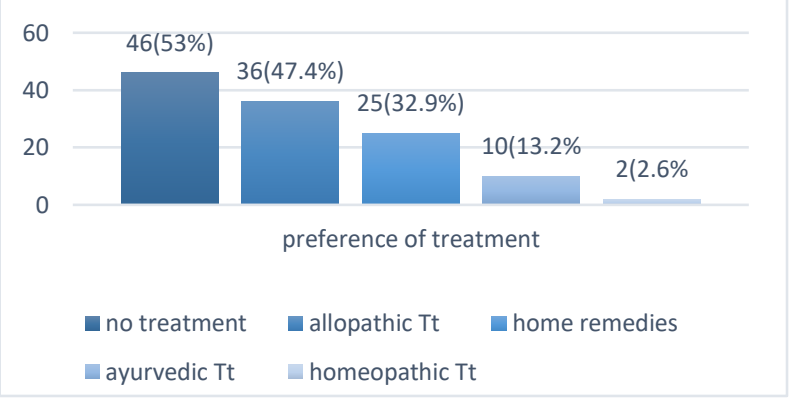

